\title{
Candidaturas independientes: vacunas para el sistema proteccionista de partidos o revitalización de las oligarquías partidistas
}

\section{Independent candidacies: vaccines against protectionist partisan system or revitalization of partisan oligarchies}

doi: https://doi.org/

10.32870/eees.v26i75.7101

\author{
María Alejandra Vizcarra Ruiz
}

\section{Resumen}

En este artículo, se revisa cuál es el papel que cumplen las candidaturas independientes en la democracia contemporánea y en la preservación o renovación de los sistemas de partidos. Se parte de la premisa de que existe la percepción de que los partidos conservan en lo posible un sistema autoproteccionista, la llamada partidocracia, basado en el monopolio de las candidaturas $y$, por tanto, de la representación y el acceso al poder público. Se demuestra, mediante revisión de antecedentes teóricos y empíricos, que frente a esta imagen de una sociedad política corrompida y estrechamente amalgamada, no sólo se presentan la indiferencia política y la apatía electoral, sino también surge la figura del ciudadano no partidista, cuya misión es desplazar la corrupción del campo de la política, esto es, su representación en partidos y políticos por igual. El material también analiza cómo la construcción de imagen de las candidaturas independientes se ha realizado enfocándolas como alternativas a la oligarquía partidista.

Palabras clave: democracia representativa, candidaturas independientes, partidocracia, partidos políticos, oligarquía partidista.

\begin{abstract}
This article reviews the role of independent candidates in contemporary democracy as in the preservation or renewal of partisan systems. As premise, there is a perception that the parties retain as far as possible a protectionist partisan system, or the so-called partidocracia, which is ultimately based on the monopoly of the candidacies and therefore on the representation and access to public power. The article shows that faced with this image of a corrupt and narrowly amalgamated political society, not only is there political indifference and electoral apathy, but also the figure of the non-partisan citizen, whose mission would be to displace corruption from the field of politics to parties and politicians alike. The text also analyzes how the image of independent candidates has been built as an alternative to the partisan oligarchy.
\end{abstract}

Keywords: Representative democracy, independent candidacies, partidocracia, political parties, partisan oligarchy.

- Profesora-Investigadora del Departamento de Estudios sobre Movimientos Sociales de la Universidad de Guadalajara, México. ORCID: https://orcid.org/0000-0002-6507-2780 alexvizcarr@yahoo.com.mx

Fecha de recepción:0I de noviembre de 2018. Fecha de aceptación: I5 de marzo de 2019 . 
Se ha vuelto un lugar común hablar de la crisis de la democracia y del desprestigio de los partidos políticos en el mundo, tanto en el ámbito académico como en otras distintas áreas de la opinión pública. Pareciera que realmente la democracia moderna, la democracia representativa, se encuentra en una fase terminal, sin que los Estados modernos encuentren una alternativa funcional y aceptable a ella. Es verdad que diversos indicadores como el Latinobarómetro muestran un deterioro cada vez mayor de la credibilidad y el apoyo de los ciudadanos a la democracia y a los partidos políticos, y que el Eurobarómetro, además, manifiesta una gran duda respecto a que las elecciones no puedan ser manipuladas desde el exterior. La participación electoral disminuye en ciertos ejercicios de voto a niveles preocupantes, y los procesos electorales parecen ser la puerta de acceso a corrientes políticas que no son precisamente defensoras de la democracia.

Por otra parte, el desprestigio de los partidos políticos va acompañado de los constantes señalamientos de actos de corrupción en los Gobiernos emanados de ellos, en los que no sólo aparecen implicados algunos de sus líderes políticos, sino que también, como sucedió recientemente en España, las estructuras completas de los partidos son señaladas a niveles judiciales como corruptas. ${ }^{1}$

Es decir, los partidos políticos parecieran constituir posibles cárteles criminales que usan los espacios públicos para cometer ilícitos de manera estructurada, tanto para beneficio personal de sus líderes y su burocracia como para garantizarse condiciones favorables que aseguren su continuidad en los espacios de representación y gobierno. Estas acciones no son legítimas, sino que los partidos recurren al

I. En 2018, la Audiencia Nacional de España encontró elementos para condenar por corrupción por primera vez a un partido político: al Partido Popular se le impuso una multa de EUR 245000.00 por malversación y blanqueo de capitales (Fuentes, 2018). 
abuso de poder para impedir en lo posible las sanciones a las que pudieran hacerse acreedores por caer en la ilegalidad.

Lo anterior se vincula también con la idea de una casta u oligarquía de los administradores, burócratas y líderes de los partidos: estos constituyen una élite política, pues independientemente de sus ideologías y programas, o de ser Gobierno u oposición, encuentran una identidad básica fundamentada en intereses comunes, lo cual lleva a que todos los miembros de los aparatos de todos los partidos tiendan a protegerse mutuamente en una especie de pacto mafioso.

El fenómeno planteado ha provocado reacciones que van desde el desinterés en las actividades políticas, y en particular respecto a la participación en los procesos electorales (con el consabido incremento de la abstención del voto), hasta la búsqueda de alternativas fuera del sistema, pasando por la participación electoral apartidista o independiente respecto a los partidos. No obstante, lo primero parece hacerle un mayor daño a la democracia:

[...] no hay nada más grave para una democracia que su población se encuentre desinteresada por la cuestión pública. Esta situación lleva a que, por una parte, las personas se replieguen en el ámbito de lo familiar o lo privado, y por la otra, a que la administración de los asuntos públicos quede exclusivamente en manos de la clase gobernante. (Raphael, 2007, p. 68)

Todo lo hasta aquí señalado lleva a que comúnmente se hable de crisis de la democracia.

También existe la percepción de que los partidos intentan, hasta que la crisis de la democracia los obliga a abrir espacios a la ciudadanía apartidista, conservar en lo posible un sistema proteccionista de partidos, o la llamada partidocracia -considerada esta como el Estado de los partidos-, finalmente sustentado en el monopolio de las candidaturas y, por tanto, de la representación y el acceso al poder público. 
Frente a esta imagen de una sociedad política corrompida y estrechamente amalgamada, cual clase social o secta secreta, no sólo se presentan la indiferencia política y la apatía electoral, sino que también surge la figura o idea del ciudadano no partidista, casi apolítico, como impoluto mesías cuya misión sería desplazar la corrupción del campo de la política, es decir, la representada en partidos y políticos por igual.

En medio de este fenómeno, se ha venido construyendo la imagen de las candidaturas independientes, o también mal llamadas ciudadanas, ${ }^{2}$ como una fórmula que permite hacer frente a ese modelo proteccionista de partidos. Frente a esta percepción, que en México parecería adquirir rango del llamado sentido común, se vuelve necesario revisar el origen y el concepto mismo de los partidos políticos y de la democracia moderna, así como la idea de su crisis y de las candidaturas independientes funcionando como vacunas eficientes para evitar la consolidación de las oligarquías partidistas.

En realidad, puede decirse que

en fechas recientes, la discusión sobre las características y las funciones de los partidos se ha incrementado a escala incluso del debate político cotidiano, lo que en el nivel teórico ha suscitado una reflexión ulterior acerca de su eventual crisis o transformación. (Vizcarra, 20I3, p. 4I)

Suele pensarse que los partidos políticos son consustanciales a la democracia moderna desde sus orígenes, como si

2. En realidad, el término ciudadano comprende a cualquier habitante de un país que cumple con los requisitos que establece su constitución, tales como haber nacido en dicho país o ser hijo de ciudadanos, contar con una edad mínima y disponer de goce de sus derechos cívicos y políticos, lo que implica que sean ciudadanos por igual el joven abstencionista y el empresario apartidista o el presidente de la república, al igual que todos los militantes de partidos y funcionarios del Gobierno. Por tanto, hablar de candidatos ciudadanos es referible a cualquier candidato. 
esta hubiese nacido ya adulta y con sus respectivos sistemas de partidos.

$\mathrm{Al}$ respecto, es importante revisar el sentido histórico tanto de la democracia representativa como de los partidos que hoy le dan vigencia. Si bien la democracia moderna tiene antecedentes en los procesos revolucionarios en Europa, en particular en Gran Bretaña (1642) y Francia (1789), y en la Independencia de los Estados Unidos (1776) - esta última constitutiva de la primera expresión del modelo republicano democrático en el mundo moderno-, no puede dejar de observarse que la constitución de los regímenes democráticos fue un proceso de larga duración que comenzó con la defenestración de los Estados absolutistas y la ruptura de los lazos coloniales, a lo cual siguió un largo proceso de avances paulatinos -y en ocasiones retrocesos-, que fueron trazando la democracia tal como hoy la conocemos.

Por otra parte, la aparición de nuevas formas de poder económico que no estaban presentes cuando surgieron las democracias modernas, que han estructurado diversas formas de copar el poder político, constituidas en poderes fácticos, que escapan a los controles democráticos tradicionales, también determina que la democracia hoy día se vea cuestionada en su concepción original de expresión de la soberanía popular por encima de cualquier otro poder, y a su vez pone en duda su capacidad de garantizar la representación real de los ciudadanos en la toma de decisiones políticas y en la administración del Estado.

Aquí cabe recordar que el largo proceso constitutivo de la democracia, si bien surgió de la idea de la soberanía emanada del pueblo frente a la medieval idea del poder por delegación divina, en realidad no fructificó de inmediato en un sistema democrático pleno ni mucho menos. Más aún, si bien ya desde la Revolución inglesa, en el siglo XVII, asentó al parlamentarismo como un fuerte contrapeso del jefe de Estado, y si bien la Revolución francesa, en el siglo XvIII, 
estableció las bases de los derechos civiles y políticos de los ciudadanos y terminó con el derecho divino como fuente del poder político, no fue sino hasta el transcurso del siglo XIX que la incipiente democracia europea fue pasando de censitaria a universal (masculina, en el sentido de ejercida sólo por varones), mientras que en Estados Unidos el voto además de censitario fue incluso, hasta bien entrado el siglo xx en algunos estados, un voto racial.

En cuanto a la universalidad del voto, este mantuvo excluida durante muchos siglos a la mitad de la humanidad, pues con la excepción de Nueva Zelanda, que lo reconoció a finales del siglo xIX, el voto de la mujer no fue posible sino hasta entrado el siglo xx, más aún, países como México apenas lo alcanzaron hasta iniciada la segunda mitad de ese siglo, mientras que en algunas naciones del medio oriente y África apenas en el siglo xxI comenzó a ser reconocido ese derecho.

Por otra parte, los partidos políticos no surgieron a la par de la democracia moderna. En sus inicios, la idea de un partido, al que en muchas ocasiones se veía como equivalente a una facción, fue establecida como algo negativo para la democracia y responsable de dividir a la nación.

Con el tiempo, Sartori señala que "El término 'partido' empezó a utilizarse, sustituyendo gradualmente la idea de que un partido no es forzosamente una facción, que no es forzosamente un mal y que no perturba forzosamente el bonum commune (el bien común)" (1994, p. 17), y si bien se le concedía la posibilidad de no ser forzosamente negativo y perturbador, quedaba abierta la puerta para que sí tuviera ese carácter, mientras que por otro lado no quedaba claro cuáles serían las bondades de su existencia.

Y aunque la idea ya estaba presente por lo menos desde "la segunda mitad del siglo XvIII cuando Voltaire afirmó concisamente en la Encyclopédie: 'El término partido no es, en sí mismo odioso, el término facción siempre lo es”' (Sartori, 
1994, p. 17), en realidad incluso durante la primera mitad del siglo xix el partido no sólo era considerado no necesario para la democracia, sino que se le rechazaba por seguir siendo visto como un factor de división social. Ese era, por ejemplo, el discurso de los padres fundadores de Estados Unidos, el primer país en el que aparecieron los partidos políticos en el sentido moderno del término.

De hecho, el politólogo francés Maurice Duverger, tal vez el más reconocido autor en la temática de partidos políticos, sostenía a mediados del siglo xx que

Los verdaderos partidos datan de apenas hace un siglo. En 1850 ningún país del mundo (con excepción de los Estados Unidos) conocía partidos políticos en el sentido moderno de la palabra: había tendencias de opiniones, clubes populares, asociaciones de pensamiento, grupos parlamentarios, pero no partidos propiamente dichos. En 1950, estos funcionan en la mayoría de las naciones civilizadas, esforzándose las demás por imitarlas. (Duverger, 1994, p. 15)

Es decir, en apenas un siglo los partidos políticos pasaron de la inexistencia real a constituirse en los elementos más importantes de la democracia moderna, apenas tras el ciudadano y luego de pasar por un largo periodo de rechazo. Los partidos tuvieron que pasar de ser vistos como facciones que representaban intereses particulares y hasta espurios a conformar grupos consolidados de intereses políticos comunes: "Los partidos políticos llegaron a ser aceptados -de forma subconsciente, e incluso así con una enorme renuencia- al comprenderse que la diversidad y el disenso no son necesariamente incompatibles con, ni perturbadores de, el orden político" (Sartori, 1994, p. 33).

Pero ¿qué es lo que hizo que un partido fuera tan relevante para la democracia moderna? Duverger afirma que "el desarrollo de los partidos parece ligado al de la democracia, es decir, a la extensión del sufragio popular y de las 
prerrogativas parlamentarias" (Duverger, 1994, p. 15), esto porque conforme aumentaron las funciones parlamentarias y se multiplicó el derecho al voto, los políticos necesitaron agruparse por afinidades y organizarse para dar a conocer a sus candidatos y canalizar el voto hacia ellos, es decir, "el nacimiento de los partidos políticos está ligado, pues, al de los grupos parlamentarios y los comités electorales" (Duverger, 1994, pp. 15-16). Esto significa que conforme la democracia se profundizó y se extendió el derecho al voto, los partidos, que hasta entonces apenas lograban diferenciarse de las facciones y las sectas políticas, se volvieron cada vez más necesarios para que funcionara el sistema democrático.

Por otro lado, los partidos también se volvieron indispensables en la medida en que el disenso -y con este el pluralismo- se convirtió en elemento fundamental para la democracia, pues es a través de los partidos políticos que el disenso se expresa y se procesa en un abanico de divergencias para encontrar puntos de acuerdo y consensos entre las diversas expresiones de la sociedad representadas en las asambleas o parlamentos. Asimismo, los partidos políticos se constituyeron en canales de participación de proyectos y grupos sociales para buscar el Gobierno, o en su caso formar oposición con capacidad de crítica y propuesta de alternativas a las políticas de la fuerza gobernante, para eventualmente sustituirla.

Por otro lado, los diversos intereses de las sociedades modernas solamente pueden traducirse en legislación y en políticas específicas por la intermediación de los partidos políticos a través sus grupos parlamentarios y de los Gobiernos cuando estos los encabezan (Vizcarra, 2013, p. 157). Hace ya casi un siglo, el doctrinista y jurista alemán Hans Kelsen advertía la imposibilidad del individuo de incidir en el Estado desde fuera de los partidos políticos: 
Es patente que el individuo aislado carece por completo de existencia política positiva por no poder ejercer ninguna influencia efectiva en la formación de la voluntad del Estado y que, por consiguiente, la democracia sólo es posible cuando los individuos, a fin de lograr una actuación sobre la voluntad colectiva, se reúnen en organizaciones definidas por diversos fines políticos, de tal manera que entre el individuo y el Estado se interpongan aquellas colectividades que agrupan en forma de partidos políticos las voluntades políticas coincidentes de los individuos. (Kelsen, 1934, pp. 36-37)

Ya entonces, el mismo Kelsen preveía que la democracia sería indistintamente una partidocracia, al afirmar contundentemente que "Sólo por ofuscación o dolo puede sostenerse la posibilidad de la democracia sin partidos políticos. La democracia, necesaria e inevitablemente, requiere de un Estado de partidos" (Kelsen, 1934, p. 37).

Precisamente, el mismo autor veía en el concepto mismo de democracia, en tanto que Gobierno del pueblo, el origen de los partidos políticos como una necesidad histórica:

ya que preliminarmente no existía el "pueblo" como potencia política, el desarrollo democrático induce a la masa de individuos aislados a organizarse en partidos políticos, y con ello despierta originariamente las fuerzas sociales que con alguna razón pueden designarse con el nombre de "pueblo". (Kelsen, 1934, p. 45)

En este sentido, resulta claro que si bien los partidos políticos no nacieron con la democracia y, más aún, que en un principio se les consideró como algo negativo que provocaba la disolución de la unidad social, con el progreso de aquella y su cada vez mayor complejidad, pasaron a constituirse en entes no sólo útiles sino necesarios para el funcionamiento de la democracia.

Ahora bien, junto con su surgimiento, comenzaron también a emerger desde la democracia misma condiciones 
que empujaban cada vez más a cuestionar el papel de los partidos como instrumentos para la democracia, y que los constituían más bien en estructuras para generar élites distanciadas y aisladas de las masas a las que pretendían representar y que se autorregulaban para constituirse en indispensables frente al ciudadano común, lo que a su vez creaba barreras inaccesibles para que estos los pudieran sustituir. Igualmente, los partidos construían puentes con sus pares para protegerse mutuamente, lo que constituía una oligarquía inaccesible e inamovible.

Quien desarrolló más una teoría al respecto fue Robert Michels, quien articuló lo que se conoció como la ley del hierro de la oligarquía de los partidos, que permitía ver que la democracia era algo que interesaba a los partidos políticos no para aplicarla en su interior, sino sólo para utilizarla en la lucha por el poder político. De hecho, según Michels, la democracia interna sería realmente un lastre para las campañas políticas:

En un partido, y sobre todo en un partido de lucha política, la democracia no es para el consumo interno, sino un artículo de exportación. Toda organización política necesita un "equipo liviano que no estorbe sus movimientos". La democracia es incompatible en todo con la rapidez estratégica, y las fuerzas de la democracia no se prestan para rápidos despliegues de una campaña [...] es esa la razón de que en sus constituciones estos partidos muestren, si bien no un cesarismo incondicional, al menos tendencias oligárquicas y centralizadoras muy fuertes. (Michels, 199la, pp. 87-88)

Para este autor, el acceso a algún espacio de poder tendría un efecto tal sobre los líderes y los dirigentes de los partidos que los transformaría independientemente de que esto no estuviera originalmente en sus expectativas o intereses, señalando que "Quien ha adquirido poder se esforzará siempre por consolidarlo y extenderlo, por multiplicar las 
murallas que defienden su posición, y por sustraerse del control de las masas" (Michels, 1991b, pp. 10-11).

Eso no implicaría que no se diesen luchas para recuperar la democracia y desplazar a la oligarquía del momento, sin embargo, la visión pesimista del teórico sostiene que al final los demócratas triunfantes volverían a repetir la misma historia, y a su vez se verían cuestionados por otros liderazgos excluidos de la nueva élite, esto repetido de manera inacabable:

Las corrientes democráticas de la historia parecen ondas sucesivas, que rompen sobre la misma playa y se renuevan constantemente. Este espectáculo constante es al mismo tiempo alentador y depresivo: cuando las democracias han conquistado ciertas etapas de desarrollo experimentan una transformación gradual, adaptándose al espíritu aristocrático, y en muchos casos también a formas aristocráticas contra las cuales lucharon al principio con tanto fervor. Aparecen entonces nuevos acusadores denunciando a los traidores; después de una era de combates gloriosos y de poder sin gloria, terminan por fundirse con la vieja clase dominante, tras lo cual soportan, una vez más, el ataque de nuevos adversarios que apelan al nombre de la democracia. Es probable que este juego cruel continúe indefinidamente. (Michels, I99 Ib, pp. 195-196)

Ahora bien, esta visión cíclica y pesimista no corresponde con otras teorías más actuales, que reconocen que la democracia sufre en el mundo una pérdida de credibilidad precisamente por quedarse al margen o ser sometida al dominio de las grandes fuerzas económicas, que no representan más que a una ínfima parte de la humanidad, pero también encuentran que la democracia, aunque puede decirse que está vacía de contenido, tiene a su vez potencialidades que pueden permitir que el ciudadano recupere protagonismo e incluso hablar de un giro hacia una democratización de la democracia. 
En este contexto es que la participación del ciudadano adquiere mayor sentido y relevancia para la democracia $\mathrm{y}$, entre otros aspectos, las candidaturas independientes parecieran ser parte de esta lucha contra la partidocracia.

Esta visión renovada plantea una recuperación de la política desde una perspectiva que le permita al ciudadano reconstituirse como el eje central de la vida democrática, y que recorra los límites que son impuestos al mismo y que este se autoimpone, tras lo cual amplíe sus libertades:

El arte de la política, cuando se trata de política democrática, se ocupa de desmontar los límites de la libertad de los ciudadanos, pero también de la autolimitación: hace libres a los ciudadanos para permitirles establecer, individual y colectivamente, sus propios límites, individuales y colectivos. (Bauman, 200I, p. 12)

Es necesario señalar que se reconoce el indudable papel que cumplieron los partidos para pasar de la limitada e incompleta democracia censitaria y de voto indirecto (esto último, por lo demás, aún permaneciente en la democracia norteamericana) a la moderna democracia representativa, a la vez que cumplieron un rol de representación social, expresando los intereses de las clases a las que acudían en busca de su voto y una ideología que se correspondía con la concepción del mundo que pretendían representar. Sin embargo, también se destaca cómo ahora han caído en total aislamiento frente a los ciudadanos y están desconectados de los intereses de sus electores.

$\mathrm{Al}$ respecto, Pierre Rosanvallon señala que si bien

Los partidos políticos fueron las organizaciones que tuvieron el papel protagónico en el funcionamiento del modelo parlamentario representativo de la democracia [...], marcaron una ruptura con el viejo mundo de las redes de notables que regían la vida política y parlamentaria en la primera era del sufragio censitario o del sufragio en dos niveles [...]. Más

\section{0}


Candidaturas independientes: vacunas para el sistema proteccionista...

allá de su funcionalidad electoral parlamentaria, tuvieron de ese modo un papel de representación social. Expresaron clases e ideologías, es decir, intereses y visiones de la sociedad y de su devenir. (Rosanvallon, 20I5, p. 27)

Sin embargo, pareciera que con la llegada del capitalismo salvaje, del neoliberalismo y el sometimiento de los Estados al capital financiero internacional,

Esos partidos vieron la erosión y luego la desaparición, a partir de la década de 1990, de esta última función representativa [...], se han alejado del mundo vivido y su lenguaje resuena en el vacío, saturado de categorías y expresiones abstractas que ya no evocan lo que la gente vive sensiblemente. (Rosanvallon, 2015, pp. 28-29)

Por otro lado, para Rosanvallon también parece que la ocupación de espacios de poder y de la administración pública ha tenido un efecto similar al descrito por Michels en su teoría de la ley del hierro de la oligarquía, esto en cuanto a la burocratización de los partidos y su alejamiento de la masa de sus electores: "es el deslizamiento hacia el Ejecutivo el que explica que los responsables políticos estén cada vez más alejados de la sociedad y profesionalizados, convertidos en puros hombres y mujeres del aparato" (Rosanvallon, 2015, p. 30).

Como ya se dijo, este desgaste en el sistema de partidos ha generado propuestas optimistas, que incluso asumiendo que pueden tener un carácter antisistémico, entendido este como propio de una oposición cuyas creencias se contraponen a los valores del orden político vigente y que tienden a deslegitimar al régimen (Vizcarra, 2013, p. 42), intentan presentar alternativas viables y atractivas para rescatar la democracia.

No se trata de ninguna manera de revoluciones o movimientos violentos o ilegales, sino de un "movimiento que reuniendo los orígenes 'insurreccionales' de la ciudadanía 
[...] le confiere la forma de un devenir institucional [...], una resistencia activa a los procesos de 'democratización' en marcha, que son una manera de cerrar la historia de la ciudadanía y del 'concepto de la política' que ella designa" (Balibar, 2013, pp. 9-10), lo que puede resumirse en el concepto ya adelantado de democratización de la democracia.

Este surgimiento de alternativas democráticas, pese a la decepción con la democracia y la irritación social que han traído las crisis económicas y el incremento de la desigualdad y de la sobreexplotación de los trabajadores en el mundo, sugiere una lucha que parece darse en los marcos democráticos y legales. Incluso, el desencanto democrático y los altibajos del abstencionismo no han terminado en una situación de desinterés tal que pueda poner en cuestión la legitimidad de las elecciones por la baja participación electoral. Como señala Rancière:

No es verdad que estemos asistiendo a un avance irrefrenable de la abstención. Por el contrario, en el elevado número de electores que persisten en movilizarse para elegir entre representantes equivalentes de una oligarquía de Estado que dio tantas pruebas de su mediocridad, cuando no de su corrupción, habría que ver más bien la señal de una admirable constancia cívica. (2012, p. 109)

Este civismo se manifiesta aun cuando la democracia existente realmente tiende a negar cada vez más sus propios fundamentos, como el pluralismo que "[...] es cuestionado en nombre de su propia defensa, en particular en los ámbitos 'cultural' y 'religioso', a menudo reactivando la vieja idea según la cual la libertad no debe favorecer a los 'enemigos de la libertad"' (Balibar, 2013, p. 188).

Dicha negación de la democracia moderna de sus fundamentos pone en evidencia la crisis del modelo democrático liberal, subsumido por el neoliberalismo, e invariablemente conduce a una reflexión profunda sobre democracia y ciu- 
dadanía (Balibar, 2013, p. 199) en el contexto actual y "a incorporarle 'estratégicamente' a la idea de 'democratización de la democracia' una dimensión de ciudadanía reflexiva, relacionada con las luchas de su propia historia" (Balibar, 2013, p. 202).

Por lo señalado, se ha vuelto muy importante el cuestionamiento del monopolio de la representación política y del Gobierno que tienen los partidos por la vía de las candidaturas, e incluso cuando están permitidas las candidaturas independientes, por el control que tienen en los hechos de todos los procesos que tienen que ver con la vida político-electoral. Esto ya lo señalaba desde antes el propio Duverger: "El monopolio jurídico de los partidos es generalmente menos importante que el monopolio de hecho: de nada sirve dejar en libertad total a los candidatos fuera de los partidos, si los candidatos de los partidos son los únicos que tienen una oportunidad de éxito en tiempos normales" (Duverger, 1994, p. 380).

En efecto, más allá de los triunfos en alcandías y alguna provincia o alguna diputación, las posibilidades reales de ganar una elección presidencial con una candidatura independiente, tanto en Francia como en México o en cualquier otro lugar del mundo, son prácticamente nulas. Hay una excepción, sin embargo, en coyunturas especiales: en situaciones de gran desprestigio de la clase política y de los partidos, las oportunidades tanto para los partidos y movimientos antisistémicos como para los candidatos independientes, apartidistas, se ven incrementadas exponencialmente.

Entonces, la democracia moderna, más que viviendo una crisis, se encuentra cuestionada en sus modalidades vigentes, ya que si bien una parte de la sociedad ha dejado de considerar que esta es la mejor forma de Gobierno o siente insatisfacción con ella -lo que explica la caída del apoyo a esta el último año, por ejemplo en América Latina, a menos del 50\% (Latinobarómetro, 2018)-, los ciudadanos 
no renuncian masivamente a elegir a sus representantes, sino que recurren a apoyar candidatos o partidos que ofrecen tomar medidas duras contra la corrupción y la clase política, rechazan la política y los partidos tradicionales y se presentan como antisistémicos.

Asimismo, surgen propuestas de organización social que pretenden mantenerse al margen del Estado, reivindicando su autonomía para escapar de los espacios sometidos al control de los intereses de las grandes corporaciones, especialmente en pequeñas comunidades que se ven afectadas por las concesiones a compañías extractivistas, y muy especialmente entre pueblos originarios del medio rural y ocasionalmente de zonas urbanas precarias.

Así, aparece

Un alejamiento de los conceptos de vanguardia política y/o formas tradicionales y parlamentarias de representación hacia unos principios de horizontalidad y democracia directa o participativa; un alejamiento de formas de unidad que suprimen o trascienden la diversidad y la pluralidad hacia la creación de relaciones de cooperación y deliberación que respetan la autonomía y generan una capacidad de flexibilidad. (Colectivo Política en Red, 2007, p. I3)

En este contexto, también tiene lugar el surgimiento de alternativas electorales no partidistas que se presentan como "una crítica a la idea predominante de la política, que refleja la menguante legitimidad de las instituciones políticas tradicionales y la definición de política que apuntala a estas, y la creciente desconfianza que inspiran los partidos políticos" (Colectivo Política en Red, 2007, p. 85). No es, pues, la democracia la que desaparece, sino las viejas formas de hacer política, que se ven rebasadas o abandonadas, sustituidas por nuevas formas de organización social, por partidos u organizaciones que son antisistémicos pero que compiten en el marco de la normatividad electoral y 
se someten a sus reglas, o por ciudadanos sin partido que utilizan las fórmulas de las candidaturas independientes.

Es decir, o bien el Estado, sus instituciones políticas y en consecuencia sus partidos, sus sistema de partidos y su clase política se ven excluidos de la participación en la vida política local protagonizada por diversos núcleos de ciudadanos, o bien los partidos tradicionales, sus élites y su vieja clase política son desplazados por partidos o grupos políticos cuya intención principal es la de acabarlos, o bien los ciudadanos se posicionan de los espacios de representación, quitándole a los partidos el monopolio real de la representación, monopolio que es roto ya sea por la emergencia de partidos nuevos o de candidatos apartidistas en tiempos de crisis de credibilidad de los partidos tradicionales, los políticos y la propia democracia. Todo esto tiene como consecuencia el fin del hasta ahora vigente sistema de partidos, tal como se ha visto en el último año (2018-2019) en países como Brasil, México o España, o un poco antes en Francia o en Italia.

Ante este panorama, comienza a predominar la idea del fin no de la democracia sino de su instrumentación por partidos y organizaciones que no comparten necesariamente su valor o que incluso pueden ir en contra de este. Desde su pureza apartidista y de grupos que se autodenominan portadores de los valores de la ciudadanía, contrapuesta a los políticos, existen ya los actores que se posesionan del espacio público hasta entonces reservado, ya sea jurídicamente o en los hechos, a los partidos y las élites políticas:

Esta idea acaba con el monopolio de los partidos políticos sobre la política [...]. Incluso la actividad electoral deja de ser territorio exclusivo de los partidos. Los partidos no son una condición necesaria para la actividad electoral, y la actividad electoral no es la única actividad de un partido político. (Colectivo Política en Red, 2007, pp. 85-86) 
Este fenómeno permite que se recupere la idea de la representación, que hasta ahora aparecía asociada a "alineación, separación y, a menudo, a una presunción de superioridad" (Colectivo Política en Red, 2007, p. 86). De nuevo, los ciudadanos estarían representados por pares, ciudadanos comunes, con sus mismos intereses, gustos, virtudes y defectos, y no por un miembro de una casta superior que hace ostentación de un conocimiento político y burocrático al que no tendría acceso el común de los ciudadanos.

Ante dicha modificación, ¿qué pasa, entonces, con los partidos y los sistemas de partidos asentados en las democracias occidentales? El propio Sartori (1994) ha demostrado fehacientemente que los partidos se vuelven indispensables en las sociedades en las que se ha alcanzado el sufragio universal y un grado superior de politización, por lo que

cuando la sociedad en general pasa a estar politizada, las normas de tráfico que enchufan a la sociedad en el Estado,y viceversa, se establecen conforme a la manera en la cual se estructura el sistema de partidos. En este momento, los partidos se convierten en organizaciones de canalización, y el sistema de partidos se convierte en el sistema de canalización política de la sociedad. (Sartori, 1994, p. 63)

Por supuesto que la pretensión de las comunidades que reclaman autonomía para autoorganizarse y autogobernarse está en desenchufarse del Estado, pero no es el caso del resto de la sociedad, que más bien puede optar por elegir un partido antisistémico o un candidato independiente, apartidista y ciudadano. En el primer caso, estaríamos ante una pequeña comunidad que se desenchufa políticamente del Estado, pero no adquiere una autonomía plena, pues sigue sujeta a las leyes generales, al pago de impuestos, al régimen de garantías y sanciones, y recurre a los servicios públicos que brinda el Estado. En el segundo caso, tiene lugar una recomposición del sistema de partidos, sin 
que estos dejen de ser los organismos de canalización y el sistema político, recompuesto, el sistema de canalización política de la sociedad.

Otra situación se presentaría en caso de que fuera electo para el Ejecutivo un candidato independiente. Esta situación, por lo demás, sólo puede darse en un sistema de Gobierno presidencialista o semipresidencialista, donde la jefatura de Estado y de Gobierno recae en la misma persona, ya que en los sistemas parlamentarios es el Parlamento el que elige al jefe de Gobierno a propuesta del jefe de Estado, sea este un presidente, como en Alemania, o un monarca, como en España o en Gran Bretaña, y aunque hipotéticamente pudiera darse una mayoría de representantes independientes, en los países donde se permiten las candidaturas independientes (por ejemplo, en España permanece el monopolio jurídico para los partidos), la realidad es que son los partidos los que suelen conservar la mayoría de las curules. No obstante, si bien en esta tercera posibilidad los partidos y el sistema de partidos no desaparecen, sí se ven sometidos a una violenta sacudida.

Por otro lado, el triunfo de un candidato independiente en el Poder Ejecutivo puede ser motivo del surgimiento de una tentación autoritaria en el mismo, como sucedió, por ejemplo, durante el Gobierno de Alberto Fujimori, que estuvo en el Ejecutivo del Perú durante el último decenio del siglo xx y que llegó a la Presidencia como candidato independiente en 1990. Apenas dos años después de ser electo, Fujimori disolvió el Congreso e intervino el Poder Judicial, bajo el argumento de que los partidos que controlaban el primero le impedían cumplir sus promesas de campaña pues le negaban los amplios poderes -incluso de orden legislativo- que solicitaba para tales efectos.

Luego, Fujimori convocó a un Congreso constituyente en el que, ante la ausencia de fuerzas opositoras, se aseguró una mayoría para su nuevo partido, Cambio 90, aliado de la 
derecha peruana. Más allá de cómo se desarrollaron los eventos políticos electorales subsecuentes, y de la corrupción que permeó todo el Gobierno y la violación continua de derechos humanos durante su régimen, resulta claro que el Ejecutivo independiente construyó su propia fuerza política con carácter de partido y generó un nuevo sistema de partidos desde el cual restableció la canalización política de la sociedad.

Otro caso reciente, esta vez en Francia, uno de los países más emblemáticos de la democracia en Europa, parece en parte repetir este esquema: Emmanuel Macron, un candidato joven (39 años al momento de asumir la Presidencia), que venía de colaborar como ministro de Economía en el desprestigiado Gobierno socialista saliente de François Holande, europeísta en el marco del auge del antieuropeísmo en Europa (representado en Francia por Marine Le Pen, del ultranacionalista Frente Nacional), lanzó su candidatura como independiente para las elecciones presidenciales de 2017.

Con un discurso liberal y proempresarial, crítico de la clase política francesa pero reivindicativo de los valores de Europa y de la propia Francia, Macron se asumió como "un producto del sistema meritocrático francés [...], pero nunca [...] adherido al sistema político tradicional" (Macron, 2017, p. 203), sistema al que él mismo culpaba de la fatiga democrática por la ineficiencia de la acción pública, asumiéndose a su vez como representante del "profundo deseo de renovación democrática y de compromiso ciudadano" que sentía Francia (Macron, 2017, p. 203).

Macron alcanzó un triunfo electoral histórico, al doblar a su contrincante euroescéptica en la segunda vuelta de las elecciones presidenciales, con un discurso fresco, pero que apelaba a esperanzas y no a miedos, como dijo el propio Barack Obama, entonces presidente de Estados Unidos (Macron, 2017, portada). Si bien participó como candidato independiente a la Presidencia de la republica de Francia, 
formó un movimiento alrededor de su candidatura al que, utilizando las siglas de su nombre, denominó En Marcha, y ya en la Presidencia le dio el carácter de partido y formó con él su propio grupo parlamentario, lo que aliado con otras fuerzas le permitió nombrar un Gobierno y un gabinete afines, esto porque el modelo francés de semipresidencialismo requiere para ello la aprobación de la Asamblea Nacional, es decir, el Parlamento francés.

De cualquier manera, Macron ha sido señalado por tener cierta nostalgia autoritaria, que se expresa en sus veladas referencias a Napoleón y en el impulso de una legislación laboral poco popular sin la mediación de la aprobación de la Asamblea, que le dio superpoderes para sacarla por decreto. Esto no resulta muy distante de lo hecho por Fujimori para sacar adelante las políticas acordadas con el Fondo Monetario Internacional durante su mandato. En este caso, Macron no pretende desconocer la Asamblea de su país, de la que, contrario a Fujimori, sí obtuvo los poderes extraordinarios que solicitó, pero la sociedad francesa no ha recibido con agrado las reformas laborales que llevó a cabo, y que de hecho desencadenaron una serie de protestas sociales que han ido acompañadas de la caída de su popularidad (Ayuso, 2019).

Independientemente del desarrollo de su Gobierno, Macron ya no es el ciudadano independiente que pasa de lado sin contaminarse por el sistema: ahora tiene su propio partido, y una coalición con fuerzas políticas de viejo cuño que no sólo le permiten gobernar sin contratiempos, sino que además le otorgan poderes tales que puede legislar en temas delicados e incluso con enfoques contrarios a los intereses de sus electores. Pareciera que la profecía de Michels, sobre el juego cruel que continua indefinidamente como "ondas sucesivas, que rompen sobre la misma playa y se renuevan constantemente" (Michels, 1991b, pp. 195-196) se confirma nuevamente un siglo después de su nacimiento. 
Otro caso similar, aunque en forma inversa, se ha presentado en Italia, donde las elecciones generales de 2018 llevaron al Gobierno a una coalición formada por un viejo partido xenófobo y euroescéptico, la Liga del Norte, y un movimiento electoral formado por un cómico italiano apenas en 2013 con un discurso antisistémico, el Movimiento Cinco Estrellas (M5), que ha hecho de la crítica a la corrupción intrínseca de los partidos y políticos tradicionales su discurso movilizador. Esta contradictoria coalición de Gobierno pone en evidencia cómo finalmente los nuevos actores, como el M5, terminan integrándose al sistema de partidos y formando parte del mismo sistema político que rechazan, aliados con una fuerza que representa muy claramente todo aquello contra lo que su discurso se pronuncia.

El desprestigio de los partidos políticos y los tradicionales sistemas de partidos operantes en las democracias modernas no se limita a las occidentales: incluso en el caso de la Federación Rusa, donde el prestigio del presidente Vladimir Putin es tal que ronda el $80 \%$ de popularidad, en las elecciones presidenciales este se presentó como candidato independiente a la reelección apoyado por un frente popular, esto para no arrastrar el desprestigio de su propio partido, Rusia Unida.

Dos años antes de la reelección rusa, habían tenido lugar las elecciones en Estados Unidos que llevaron a la presidencia a Donald Trump, otro ciudadano candidato, si bien en este caso de uno de los partidos tradicionales norteamericanos, el Republicano. Es relevante recordar que este personaje no sólo basó su campaña en las elecciones primarias del partido que lo candidateó en una constante crítica a las élites políticas de este partido y del sistema político norteamericano, sino que incluso amenazó con sostener su candidatura como independiente en caso de no resultar electo internamente por dicho partido. 
En América Latina, las elecciones presidenciales en Brasil, en octubre de 2018, catapultaron a un pequeño partido al que se afilió en 2017 Jair Bolsonaro, ahora presidente, para ser candidato al Ejecutivo, luego de haber recorrido diversas propuestas políticas. En el caso brasileño, de nuevo un discurso antisistémico, incluso amenazante y violento contra la élite política que había gobernado en los años posteriores a la dictadura militar, convirtió en triunfador del proceso electoral a Bolsonaro y llevó a su partido de la indigencia electoral a ser una de las fuerzas más numerosas en el Congreso nacional. De hecho, una coalición de partidos de la derecha brasileña parece estarse conformando para constituir el apoyo parlamentario del Gobierno de Bolsonaro. Aquí es dable señalar que si bien existe una recomposición del sistema de partidos brasileño, hasta ahora no hay mayor convulsión en este terreno, aun cuando se ha señalado a Bolsonaro no sólo como una figura antisistémica, sino como enemigo de la democracia y sus valores.

En México, las candidaturas independientes han tenido una breve, pero sinuosa vida. Los partidos políticos en dicho país no tuvieron el monopolio de las candidaturas sino hasta la Ley Federal Electoral de 1946, cuando fueron establecidas las normas para el reconocimiento de los partidos políticos. Hasta antes de ese año, los candidatos podían registrarse libremente, aun cuando desde diciembre de 1911 la ley electoral promovida por el maderismo (fuerza política encabezada por el revolucionario Francisco I. Madero, opuesta a la dictadura de Porfirio Díaz) reconoció por primera vez la existencia jurídica de los partidos políticos y les otorgó algunas atribuciones de carácter electoral (Vizcarra, 2002, p. 66).

La ley electoral mexicana de 1946 es conocida por federalizar el proceso electoral en el país, hasta entonces en manos de las autoridades municipales, pero también por establecer las bases jurídicas para la constitución de los partidos políticos con verdadero carácter nacional, lo que 
se podría decir que hizo acuñar el sistema de partidos del México moderno, con todas las variaciones que ha tenido en los últimos setenta y tres años.

La ley de 1946 estableció el requisito para la conformación de partidos de contar con al menos 30000 afiliados con un mínimo de 1000 en cada una de las dos terceras partes de las entidades del país, así como contar con estatutos, programa, métodos de educación política para sus agremiados, estructura y órganos de dirección, entre otros requisitos, además de establecer que únicamente los partidos políticos podrían registrar candidatos. Es decir, mediante dicha ley se creaban las bases para que México pudiera comenzar a tener partidos estables y sólidos (Vizcarra, 2002, p. 106).

Sin embargo, la figura de los candidatos no registrados permaneció por un largo tiempo en las boletas y fue motivo de burlas: Cantinflas, reconocido cómico del país, sería un recurrido candidato popular espontáneo no registrado (Garfías, 2014). También, la figura del candidato no registrado permitió expresar consignas políticas o anotar el nombre de algún candidato sostenido por partidos, frentes u organizaciones no registradas, como fue el caso de las candidaturas de la izquierda comunista de Miguel Mendoza López, en 1958, Ramón Danzós Palomino, en 1964, y Valentín Campa, en 1976 (Garfías, 2014).

Contrario a lo anterior, en algunas entidades se mantuvo el respeto por las candidaturas independientes: en 1998, en Tamaulipas, reconocieron el triunfo de un candidato no registrado en el municipio de Jiménez tanto el Instituto Estatal Electoral como el Tribunal Electoral del Estado de Tamaulipas (Campos, 2014, pp. 81-82). En otros casos, estas figuras fueron incorporadas a las constituciones estatales: Yucatán agregó en 2006 la fórmula de candidaturas independientes a dicho orden legal estatal, de tal manera que esta figura estuvo reconocida en dicho estado antes incluso 
de que se estableciera a nivel nacional (Santiago y Larrosa Haro, 2018, p. 203).

Si bien el antecedente más inmediato a las candidaturas independientes en México se sitúa en la resolución de la Corte Interamericana de Derechos Humanos (CIDH) respecto al litigio de Jorge Castañeda Gutman tras el que se reconoció que el demandante "no contó con un recurso judicial efectivo para cuestionar la negativa de su inscripción como candidato independiente al cargo de presidente del Estado mexicano [...] para las elecciones del año 2006" (Corte Interamericana de Derechos Humanos, 2013, p. 1), este caso en realidad pareciera haber sido más mediático que determinante, e incluso podría pensarse que le dio posibilidades a la Presidencia de Felipe Calderón (2006-2012) para que presentara en 2009 la iniciativa de ley para los candidatos independientes, misma que fue aprobada a nivel constitucional en 2012 y sólo ya en la norma reglamentaria en 2014. En el ínter, dicha moción del Ejecutivo permitió que se incorporara la figura de candidato independiente en entidades como Zacatecas, donde uno de estos candidatos obtuvo el triunfo en una alcaldía, y en Quintana Roo o Yucatán que, como ya se dijo, se adelantó a la reforma varios años.

Antes de las legislaciones promovidas por la Presidencia de Calderón, la demanda que presentó Castañeda en la CIDH respondía a un procedimiento iniciado por el demandante tras solicitar su inscripción como candidato independiente a las elecciones presidenciales de 2006 ante el Instituto Federal Electoral mexicano, que le había negado dicha posibilidad por no estar contemplada en la ley. Castañeda había recurrido entonces a un juzgado federal y luego a la Suprema Corte de Justicia de la Nación, que lo consideró sobreseído. Tras esto, el candidato había llevado el recurso a la CIDH, en marzo de 2007, con el argumento de que la denegación de justicia le había impedido ser candidato a la Presidencia. 
Al paralelo de estos hechos, los partidos en el Congreso habían discutido una reforma electoral que resolvía varios de los señalamientos sobre la cuestionada elección presidencial de 2006. Entre eso, debatieron la reforma en materia de medios electrónicos, cuya reforma entró en vigor a nivel constitucional en diciembre de 2007, muy cerca del nuevo Código Federal de Instituciones y Procedimientos Electorales (COFIPE), que fue aprobado en enero de 2008. El gran debate y las notas postreforma se centraron en el asunto del control estatal de la publicidad en los medios masivos de comunicación, aunque los partidos, en una manifiesta actitud oligárquica y de proteccionismo partidista, habían aprobado también la prohibición constitucional de las candidaturas independientes en las entidades federativas.

Por su parte, la mencionada resolución de la CIDH, expedida en julio de 2009, hace énfasis en que el derecho que se viola en el caso Castañeda es el de un recurso judicial efectivo, y no el derecho a ser candidato independiente. En este contexto de repliegue de los partidos en el Congreso para impedir cualquier resquicio legal para las candidaturas independientes y de una resolución judicial que conminaba a buscar una figura de acceso a la defensa legal ante la negativa de los órdenes nacionales del registro de candidaturas independientes, cabría preguntarse si la resolución de la corte interamericana impactó en la Presidencia de la república y en el Congreso, tan poco dispuesto entonces a permitir estas candidaturas, o si intervinieron otros factores, como la notable caída de la confianza en los partidos políticos a partir de la elección del 2006 en México, esto, además, en un contexto en el que la enorme mayoría de los Estados del mundo permitía ya las candidaturas independientes (Santiago y Larrosa Haro, 2018).

Más aún si se considera que la reforma electoral que permitió las candidaturas independientes en realidad no se concretó sino hasta 2014 para aplicarse en las elecciones 
intermedias de 2015, se puede pensar que la decisión tuvo más que ver con una necesidad de darle oxígeno al sistema de partidos en México que a un recurso interpuesto ante la CIDH. Es decir, las candidaturas independientes comenzaron a ser vistas como la panacea para salvar la democracia en crisis y la quiebra del sistema de partidos en México, y los partidos y políticos actuaron en consecuencia de dicha visión emergente.

Por lo demás, las candidaturas independientes mostraron en el proceso electoral de 2015 que constituían una efectiva válvula de escape para el descontento general hacia la democracia y sus instituciones, un escape que además no constituía realmente un riesgo serio para los partidos y su sistema. En el año electoral antes mencionado, algunas alcaldías pasaron a manos de candidatos independientes, muchos de ellos provenientes de los viejos y cuestionados partidos, una gubernatura fue obtenida por un candidato independiente de larga trayectoria política en el Partido Revolucionario Institucional (PRI), una diputación federal fue para un disidente del Partido Acción Nacional (PAN), y una curul local la obtuvo el único candidato independiente vencedor sin vínculos previos con algún partido (Pedro Kumamoto, en el distrito local 10 de Jalisco).

Por su parte, las elecciones federales de 2018 desinflaron las expectativas respecto al independentismo político: ningún candidato independiente a gobernador fue electo; en Jalisco, el grupo de jóvenes (Wikipolítica) que se había agrupado tras el éxito de Kumamoto en 2015 no alcanzó ningún puesto de elección; y en el caso de las candidaturas presidenciales, quedó manifestada la dificultad de alcanzar ya no digamos el triunfo, sino inicialmente el registro de independientes.

También durante dicho año, los candidatos a la Presidencia que parecían tener un fuerte apoyo de algunos sectores de la sociedad pero no de las facciones o grupos internos 
de los partidos políticos quedaron fuera de la contienda al no cubrir el número de firmas para respaldar su registro, como pasó al periodista Pedro Ferriz de Con o a la candidata del Consejo Nacional Indígena impulsada por el Ejercito Zapatista de Liberación Nacional, María de Jesús Patricio. De hecho, finalmente sólo alcanzaron registro la expanista Margarita Zavala y el expriista Jaime Rodríguez; la primera se retiró antes del final de la contienda por el débil apoyo que mostraban las tendencias electorales, mientras el segundo terminó en último lugar en la elección y con varios señalamientos de irregularidades en su contra en el proceso de obtención de firmas.

En este caso, las candidaturas independientes en el proceso electoral de 2018 no mostraron tener un impacto relevante sobre los partidos políticos. El factor que dominó la elección fue la irrupción de la candidatura largamente anunciada de un personaje muy conocido en la política mexicana, Andrés Manuel López Obrador, propuesta por un partido nuevo, el Movimiento de Regeneración Nacional (Morena), fundado por el propio candidato a partir sobre todo de figuras políticas separadas de otros partidos. Finalmente, López Obrador ganó la Presidencia, por lo que se puede decir que la ruptura del sistema de partidos no se dio por la vía de los candidatos independientes, sino por el proceso más institucional del paso de un partido de oposición a gobernante. A partir de esto, la esperanza y la confianza populares en la política y la democracia en México parecen restañarse.

Finalmente, es posible decir que si bien las candidaturas independientes actúan como un acicate para que los partidos revisen sus prácticas y se reposicionen con sus electores, o en otros casos para que se revitalice la clase política con nuevos miembros, partidos y discursos, lo que contribuye a su vez a la superación de la desconfianza y el desinterés en las instituciones de la democracia, tal parece que la vieja ley del hierro de Michels mantiene su vigencia y es visible 
cómo las viejas oligarquías sólo se renuevan pero conservan sus mismas características.

Ayuso, S. (06 de enero de 2019). Los "chalecos amariBibliografía llos" mantienen su desafío al Gobierno de Macron. El País. Recuperado de https://elpais.com/internacional/2019/0I/05/actualidad//5467/3955_0764 I8.html

Balibar, E. (20I3). Ciudadanía. Córdoba:Adriana Hidalgo.

Bauman, Z. (200I). En busca de la política. Buenos Aires: Fondo de Cultura Económica.

Campos, G.(20I4). Las candidaturas independientes en México. Revista Derecho del Estado, (julio-diciembre). Recuperado de https://www.redalyc.org/html/3376/337632740003/

Colectivo Política en Red (2007). Repensar la política en la era de los movimientos y de las redes. Barcelona: Icaria Más Madera.

Corte Interamericana de Derechos Humanos (2013). Resolución del 28 de agosto 2013 caso Castañeda Gutman vs México. Recuperado de http://www.corteidh.or.cr/docs/ supervisiones/castañeda_28_08_I3.pdf

Duverger, M. (1994). Los partidos políticos. México: Fondo de Cultura Económica.

Fuentes, F. (25 de mayo de 2018). El partido popular condenado por corrupción. Euronews. Recuperado de https:// es.euronews.com/20 I8/05/24/el-partido-popular-condenado-por-corrupcion

Garfías, F. (08 de julio de 2014). De los votos por Cantinflas al "no era penal". Excélsior. Recuperado de https://www.excelsior.com.mx/opinion/francisco-garfias/2014/07/08/9696/3

Kelsen, H. (1934). Esencia y valor de la democracia. Barcelona: Labor.

Latinobarómetro (2018). Informe [bancos en línea]. Recuperado de www.latinobarometro.org

Macron, E. (20I7). Revolución. Barcelona: Sin Fronteras. 
Bibliografía $\mid$ Michels, R. (199la). Los partidos políticos I. Buenos Aires: Amorrortu.

Michels, R. (199|b). Los partidos políticos 2. Buenos Aires: Amorrortu.

Rancière J. (20I2). El odio a la democracia. Buenos Aires: Amorortu.

Raphael, R. (2007). Para entender la institución ciudadana. Guadalajara: Instituto Electoral del Estado de Jalisco.

Rosanvallon, P. (20I5). El buen gobierno. Buenos Aires: Manantial.

Santiago, J., y Larrosa Haro, M. (2018). Candidaturas independientes. ¿Solución a la crisis de representación política? Ciencia jurídica, 7(13), 203-220. Recuperado de http://www.cienciajuridica.ugto.mx/index.php/CJ/ article/download/278/235

Sartori, G. (1994). Partidos y sistemas de partidos. Madrid: Alianza Editorial.

Vizcarra, A. (2002). El proceso de democratización en México 18/ 2-2000. Ciudad Juárez: Premio Rousset Banda 200 I Ensayo Político, Universidad de Ciudad Juárez.

Vizcarra, A. (20I3). La oposición partidista en México. El control del Gobierno y las alternativas políticas en la Cámara de Diputados. Guadalajara: Universidad de Guadalajara. 